\title{
Emergency ophthalmic surgeries during COVID-19—a Hong Kong perspective
}

\author{
Emily W. H. Tang ${ }^{1,2}$ (D) $\cdot$ Daniel H. T. Wong ${ }^{1} \cdot$ Yvonne Y. Y. Chan ${ }^{1} \cdot$ Kenneth K. W. Li ${ }^{1,2}$ (D)
}

Received: 7 May 2020 / Revised: 7 May 2020 / Accepted: 20 May 2020 / Published online: 3 June 2020

(C) Springer-Verlag GmbH Germany, part of Springer Nature 2020

Keywords COVID-19 $\cdot$ Coronavirus $\cdot$ Emergency $\cdot$ Ophthalmic surgery

Dear Editor,

We have read with interest on the letter "Practical experience on emergency ophthalmic surgery during the prevalence of COVID-19" by Hao et al. [1]. Since the outbreak of COVID-19 in Hong Kong at the end of January 2020, most elective surgeries were trimmed [2]. The situation was worsened by the strike in the first week of February, which resulted in very limited number of staff and very limited operation slots in the operation theatre. These operation slots were all reserved for emergency surgeries across different surgical streams in our hospital. In order to maximally utilize the operation slots for those who are urgently in need, each surgical specialty needed to prioritize their list of operations, so that only the most urgent cases which were life-threatening, or sight-threatening cases in ophthalmology, would be performed in the scarcity of resources. To strike the balance between tight personal protection equipment (PPE) and protection to our frontline operation staff, we have developed a risk stratification protocol with the use of epidemiological history screening with Fever, Travel, Occupation, Contact and Cluster (FTOCC) and rapid polymerase chain reaction (PCR) test for COVID-19 [3] which was proved to be effective in conservation of PPE and provide adequate protection to our operation staff.

Kenneth K. W. Li

kennethli@rcsed.ac.uk

1 Department of Ophthalmology, United Christian Hospital, Kowloon East Cluster, 130 Hip Wo Street, Kwun Tong, Kowloon, Hong Kong SAR

2 Department of Ophthalmology, Tseung Kwan O Hospital, Kowloon East Cluster, 2 Po Ning Path, Tseung Kwan O, Hong Kong SAR
We would like to share that our experiences were quite different from Hao et al. [1] in terms the types of emergency ophthalmic surgeries and case mix during the outbreak period. Their surgeries were mainly glaucoma surgery but eye trauma rare. As one of the tertiary hospital in Hong Kong, between the period of February and April 2020, we have a total of 19 emergency ophthalmic operations done, 14 cases $(73.7 \%)$ were done under general anaesthesia and 5 cases $(26.3 \%)$ were done under local anaesthesia. The most common surgery was retinal detachment surgery ( 9 cases, $47.4 \%$ ), followed by ruptured globe repair (3 cases, 15.8\%). Other surgeries included glaucoma surgery ( 2 cases, $10.5 \%$ ), eyelid cancer surgery with one required frozen section and reconstruction and the other one required enucleation ( 2 cases, $10.5 \%$ ), orbital fracture repair (1 case, 5.3\%), phacomorphic glaucoma (1 case, $5.3 \%)$ and eyelid laceration (1 case, 5.3\%). The difference may be due to different locality with different ophthalmic surgical needs.

In order to save operation slots for emergency operations and save PPE, some surgical procedures were done as office procedures or bedside procedures in our department, such as tap and inject for endophthalmitis cases and amniotic membrane transplantation for corneal thinning cases.

In addition, active solicitation of eye tissues for corneal transplantation was temporarily suspended in Hong Kong between 18th February 2020 and 30th April 2020, since those requiring urgent corneal transplant procedures are rare, and in alignment with the hospital direction to cut down elective procedures and to conserve PPE during the COVID-19 pandemic. In areas outside Hong Kong, we were aware of the enhanced surveillance such as inclusion of rapid COVID-19 testing as one of the screening tests for the donor of blood or other organs, as well as exclusion if donor has pneumonia or viral disease, respiratory or flu-like symptoms or suspected severe acute respiratory syndrome coronavirus 2 (SARS$\mathrm{CoV}-2$ ) exposure, in areas with active community COVID- 
19 outbreak in this critical period, in order to protect the recipients, who are usually immunocompromised, from contracting the infection [4-6].

We hope our experience, in conjunction with the author's study, could contribute to better management for patients requiring emergency ophthalmic surgeries during the COVID19 outbreak.

Funding information This commentary received no specific grant from any funding agency.

Data availability Not applicable

Code availability Not applicable

\section{Compliance with ethical standards}

Conflicts of interest The authors declare that they have no conflict of interest.

Patient consent The patient/next of kin/guardian has consented to the submission of the Letter to the Journal.

Consent for publication The authors consent the manuscript for publication if accepted.

\section{References}

1. Du H, Zhang M, Zhang H, Sun X (2020) Practical experience on emergency ophthalmic surgery during the prevalence of COVID-19. Graefes Arch Clin Exp Ophthalmol (Apr 20). https://doi.org/10. 1007/s00417-020-04692-x

2. Lai THT, Tang EWH, Chau SKY et al (2020) Stepping up infection control measures in ophthalmology during the novel coronavirus outbreak: an experience from Hong Kong. Graefes Arch Clin Exp Ophthalmol 258(5):1049-1055

3. Wong, HTW, Tang WHT, Njo A, et al. (2020) Risk stratification protocol to reduce consumption of personal protective equipment for emergency surgeries during COVID-19 pandemic. Hong Kong Med J 26. https://doi.org/10.12809/hkmj208533 Accessed 5 May 2020.

4. Busin M, Yu AC, Ponzin D (2020) Coping with COVID-19: an italian perspective on corneal surgery and eye banking in the time of a pandemic and beyond. Ophthalmology. https://doi.org/10.1016/ j.ophtha.2020.04.031

5. ET Health World. (2020) COVID-19 and ethics of transplantation of organs and tissues. https:/health.economictimes.indiatimes.com/ news/industry/covid-19-and-ethics-of-transplantation-of-organsand-tissues/74976048 Accessed 5 April 2020.

6. Global Alliance of Eye Banks Associations (2020) Alert up-date: Coronavirus (COVID-2019) and Ocular Tissue Donation. http:// www.gaeba.org/2020/alert-coronavirus-2019-ncov-and-oculartissue-donation/ Accessed 25 March 2020.

Publisher's note Springer Nature remains neutral with regard to jurisdictional claims in published maps and institutional affiliations. 